Revue d'histoire de l'enfance « irrégulière »

Le Temps de l'histoire

$4 \mid 2002$

Images de l'enfance et de la jeunesse « irrégulières »

\title{
Images de la jeunesse irrégulière : des lieux pour les voir
}

Michel Basdevant

\section{(2) OpenEdition \\ Journals}

Édition électronique

URL : http://journals.openedition.org/rhei/60

DOI : $10.4000 /$ rhei.60

ISBN : 978-2-7535-1642-7

ISSN : $1777-540 \mathrm{X}$

Éditeur

Presses universitaires de Rennes

Édition imprimée

Date de publication : 15 novembre 2002

Pagination : 201-202

ISSN : 1287-2431

Référence électronique

Michel Basdevant, «Images de la jeunesse irrégulière : des lieux pour les voir », Revue d'histoire de

l'enfance « irrégulière » [En ligne], 4 | 2002, mis en ligne le 30 avril 2007, consulté le 04 décembre 2020

URL : http://journals.openedition.org/rhei/60 ; DOI : https://doi.org/10.4000/rhei.60 


\section{Images de la jeunesse irrégulière : des lieux pour les voir}

Michel

Basdevant $^{(1)}$
Il nous avait semblé facile de lister les lieux ayant répertorié les films ou les documentaires traitant de "l'enfance irrégulière". Erreur! Très peu d'endroits possèdent des catalogues ou des ouvrages sur ce sujet. Les informations sont très éparpillées. Bref, le travail de rassemblement reste à faire. La liste proposée dans ce numéro est loin d'être exhaustive. Si le lecteur, notamment en province, a connaissance de bonnes adresses, qu'il n'hésite pas nous les communiquer.

Sans conteste, le Forum des images à Paris est le mieux équipé, avec la possibilité de visionner sur place, mais il ne possède que des images filmées à Paris ou en proche banlieue. L'Institut national de l'audiovisuel a un certain nombre de documents, mais ses tarifs font qu'il ne s'adresse qu'aux professionnels.

Nous avons ajouté quelques sociétés de production et de diffusion ayant un catalogue, et avec qui, les uns et les autres, nous avons travaillé.
Forum des Images

Porte Saint-Eustache

Forum des Halles

75001 Paris

Tél. : 01.44.76.62.00

ou 62.70 ou 63.59

Site : www.forumdesimages.net

Bibliothèque André Malraux 78, boulevard Raspail
75006 Paris

Tél. : 01.45.44.53.85

Couriel : bibmalraux@voilà.fr

Bibliothèque du film

et de l'image

100, faubourg Saint-Antoine

75012 Paris

Tél. : 01.53.02.22.30

Site : www.bifi.fr
(1) Vidéaste, CNRS/

Printemps.

Michel Basdevant / p. 201 à 202 
Cinémathèque française

4, rue de Longchamp

75016 Paris

Tél. : 01.53.65.74.74

Site : www.cinematheque.com

Institut national de l'audiovisuel

83, rue de Patay

75013 Paris

Tél. : 01.44.23.12.12

[ou $]$

Institut national de l'audiovisuel

4, avenue de l'Europe

94360 Brie-sur-Marne

[Les adresses électroniques de

l'INA sont nominatives.]

\section{La Cathode}

119, rue Pierre Sémard 93000 Bobigny

Tél. : 01.48.30.81.60

Site : www.lacathode.org
Centre de ressources multimédia du Val-d'Oise

3, place de la Fraternité

95300 Pontoise

Tél. : 01.30.75.09.95

CNRS/Printemps

47, boulevard Vauban

78047 Guyancourt Cedex

Tél. : 01.39.25.56.52

Couriel : michel.basdevant

@ printemps.uvsq.fr

CNFE-PJJ

54, rue de Garches

92420 Vaucresson

Tél. : 01.47.95.98.22

E-mail : bernard.alcaraz@justice.fr

Anthea-La parole donnée

7, place aux Herbes

BP 219

83306 Draguignan Cedex

Tél. : 04.94.68.98.48 